\title{
Degradation Mechanisms in $\mathrm{Li}_{2} \mathrm{VO}_{2} \mathrm{~F}$ Li-Rich Disordered Rock-Salt Cathodes
}

\author{
Ida Källquist, ${ }^{\dagger}$ Andrew J. Naylor, ${ }^{\ddagger}$ Christian Baur, ${ }^{\S}$ Johann Chable, ${ }^{\S}$ Jolla Kullgren, ${ }^{\ddagger}$

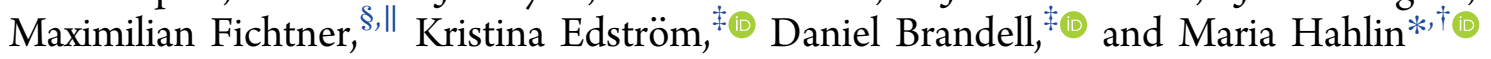 \\ ${ }^{\dagger}$ Department of Physics and Astronomy, Uppsala University, Box 516, 75120 Uppsala, Sweden \\ ${ }^{\ddagger}$ Department of Chemistry-Ångström Laboratory, Uppsala University, Box 538, 75121 Uppsala, Sweden \\ ${ }^{\S}$ Helmholtz Institute Ulm, Helmholtzstraße 11, 89081 Ulm, Germany \\ "Institute of Nanotechnology, Karlsruhe Institute of Technology, Box 3640, 76021 Karlsruhe, Germany
}

\author{
Supporting Information
}

\begin{abstract}
The increased energy density in Li-ion batteries is particularly dependent on the cathode materials that so far have been limiting the overall battery performance. A new class of materials, Li-rich disordered rock salts, has recently been brought forward as promising candidates for nextgeneration cathodes because of their ability to reversibly cycle more than one $\mathrm{Li}$-ion per transition metal. Several variants of these $\mathrm{Li}$-rich cathode materials have been developed recently and show promising initial capacities, but challenges concerning capacity fade and voltage decay during cycling are yet to be overcome. Mechanisms behind the significant capacity fade of some materials must be understood to allow for the design of new materials in which detrimental reactions can be mitigated. In this study, the origin of the capacity fade in the Li-rich material $\mathrm{Li}_{2} \mathrm{VO}_{2} \mathrm{~F}$ is investigated, and it is shown to begin with degradation of the particle surface that spreads inward with continued cycling.
\end{abstract}

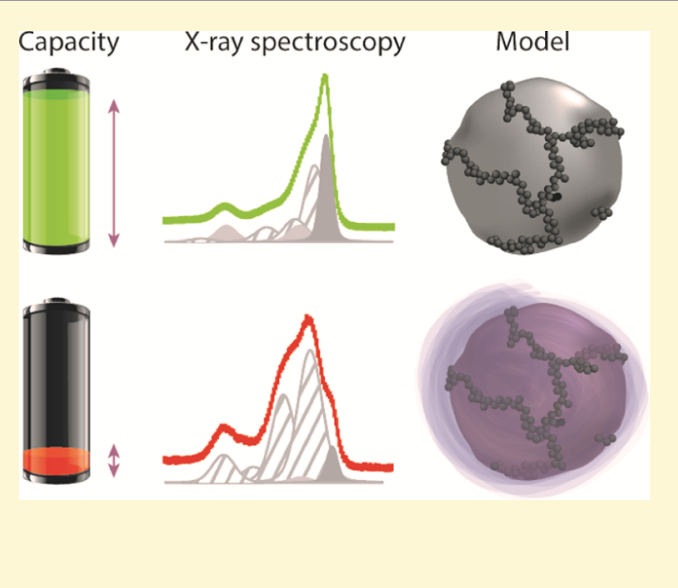

\section{INTRODUCTION}

Lithium-rich cathode materials are becoming increasingly interesting for use in lithium-ion batteries because of their ability to extract more than one Li-ion, making better use of the theoretically available charge compensation of the transition metal (TM) ${ }^{1-3}$ Together with the possibility for anionic redox reactions, ${ }^{4-6}$ these materials offer potentially greater capacities $\left(\sim 300 \mathrm{~mA} \mathrm{~h} \mathrm{~g}^{-1}\right)$ over current state-of-theart cathode materials, for example, NMC $\left(200 \mathrm{~mA} \mathrm{~h} \mathrm{~g}^{-1}\right)$, LCO, or LMO (both $140 \mathrm{~mA} \mathrm{~h} \mathrm{~g} \mathrm{~g}^{-1}$ ), thus resulting in increased energy density demanded for instance by the electrical vehicle market. ${ }^{7-9}$

In Li-rich oxyfluorides, some oxide anions $\left(\mathrm{O}^{2-}\right)$ are interchanged with fluoride anions $\left(\mathrm{F}^{-}\right)$. The single negative charge of fluoride allows for lower oxidation states of the TM in the pristine material and, together with lithium in excess, offers the possibility of multivalent redox reactions. Additionally, the higher electronegativity of fluorine compared to oxygen increases the operating voltage, which when coupled with higher theoretical capacities would give higher energy densities. ${ }^{10-12}$ Anion substitution has also been shown to improve the electrochemical cycling stability for different electrode materials..$^{10,13-17}$ One promising cathode material within this group of materials is the Li-rich disordered rock-salt $\mathrm{Li}_{2} \mathrm{VO}_{2} \mathrm{~F}$, introduced by Chen et al. in $2015 .^{12}$ The multivalent $\mathrm{V}^{3+} / \mathrm{V}^{5+}$ redox couple together with the incorporation of ideally two $\mathrm{Li}^{+}$per TM results in an impressive theoretical capacity of $462 \mathrm{~mA} \mathrm{~h} \mathrm{~g}^{-1}$. Not all of lithium can be extracted from the structure because of stability constraints, but previous studies have shown experimental capacities as high as $420 \mathrm{~mA}$ $\mathrm{h} \mathrm{g}^{-1}$ (i.e., $1.8 \mathrm{Li}^{+}$per TM) ${ }^{12,18,19}$ Moreover, $\mathrm{Li}_{2} \mathrm{VO}_{2} \mathrm{~F}$ exhibits small volume expansion and no crystalline phase transitions during charge/discharge, ${ }^{12}$ resulting in little stress within the material lattice.

Despite their distinct advantages, Li-rich cathode materials in general and $\mathrm{Li}_{2} \mathrm{VO}_{2} \mathrm{~F}$ in particular suffer from substantial capacity fade and increased polarization upon cycling. These are challenges which need to be addressed for further development of these materials. Other studies on vanadiumbased cathode materials ${ }^{20-23}$ suggest that vanadium dissolution can occur at low voltages, which could thus be a reason for severe capacity fading observed for $\mathrm{Li}_{2} \mathrm{VO}_{2} \mathrm{~F}$. For Li-rich layered cathode materials, poor performance has been explained by a combination of oxygen loss, metal dissolution/trapping, and structural deterioration, ${ }^{2,24-28}$ while for disordered materials, a high degree of oxygen redox activity leading to oxygen loss has been blamed. ${ }^{2-33}$ The oxidized oxygen or released oxygen gas can, in turn, trigger further

Received: February 27, 2019

Revised: $\quad$ May 29, 2019

Published: June 3, 2019 
reactions with the electrolyte, leading to the formation of a surface layer. ${ }^{29,30,34}$

On anodes, this surface layer has been called a solid electrolyte interphase $(\mathrm{SEI})^{35,36}$ while the terminology for cathodes is less consistent, where the cathode electrolyte interphase $^{37-39}$ and solid permeable interface $e^{40-42}$ are two concepts used. In this paper, we choose to use the term "interphase layer" because its behavior in many aspects shows to be more similar to an SEI but on a cathode surface. A wellfunctioning interphase layer will passivate the electrolyte/ electrode interface and prevent further degradation of the material while still allowing unhindered Li-ion diffusion and can thus significantly improve the cycling performance. ${ }^{4-45}$

Because most critical reactions occur at the interfaces within a battery, it is a commonplace to study the electrode surfaces in order to evaluate the effect of any detrimental reactions. Photoelectron spectroscopy (PES) has a high surface sensitivity together with chemical sensitivity. This enables local bonding environments and/or oxidation states to be probed, making it a particularly suitable method to study battery interfaces. $^{41,50-52}$ In addition, by using synchrotron radiation, the incoming photon energy can be tuned to achieve different probing depths, and thus, a nondestructive depth profile of the material can be achieved. ${ }^{53,54} \mathrm{X}$-ray absorption spectroscopy (XAS) is an alternative yet a complementary technique to PES, which probes valence states, also yielding oxidation states and local bonding environments. ${ }^{55,56}$ Being a photon in-photon out process, XAS features a deeper probing depth $(>100 \mathrm{~nm})$ that allows the whole bulk of the material to be probed ${ }^{57-59}$ as compared to PES.

In this study, we make a detailed analysis of the mechanisms behind the observed capacity fading in $\mathrm{Li}_{2} \mathrm{VO}_{2} \mathrm{~F}$ by PES and XAS. Combining energy-tuned PES with XAS enables a thorough investigation of the build-up, thickness, and composition of the interphase layer as well as probing redox reactions at the near-surface to the bulk of active material (AM) particles. The different probing regions are illustrated in Figure 1. To understand how degradation proceeds during

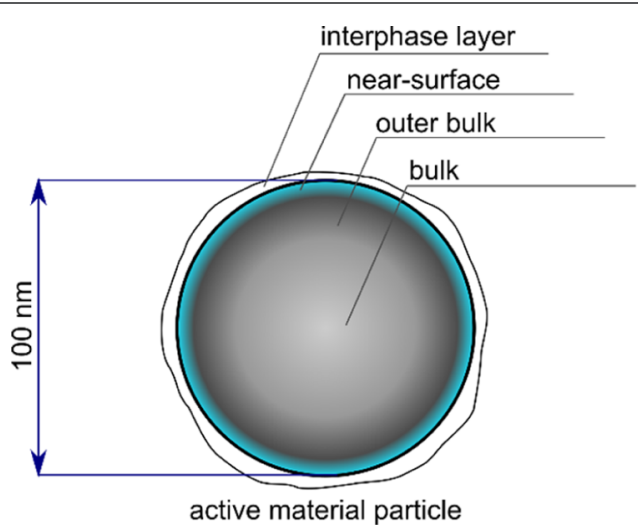

Figure 1. Schematic illustration of an AM particle showing different regions that are being probed with PES and XAS.

cycling, comparisons are made of electrodes aged up to 50 cycles in both lithiated and delithiated states. Advanced spectroscopic measurements demonstrate that the material degradation begins at the near-surface with the conversion of the AM to new redox-inactive vanadium compounds, a process which continues into the bulk upon extended cycling and results in the irreversible paralysis of the AM.

\section{EXPERIMENTAL SECTION}

Synthesis. All the following steps were performed in an argonfilled glovebox with water and oxygen levels below $0.1 \mathrm{ppm}$. The $\mathrm{Li}_{2} \mathrm{VO}_{2} \mathrm{~F}$ material was prepared by following the mechanochemical ball milling procedure as described elsewhere. ${ }^{0,12,18,60}$ The precursors used were $\mathrm{V}_{2} \mathrm{O}_{3}$ (Alfa Aesar, 99.7\%), $\mathrm{Li}_{2} \mathrm{O}$ (Alfa Aesar, 99.7\%), and $\mathrm{LiF}$ (Alfa Aesar, 99.9\%). For the electrode preparation, $\mathrm{Li}_{2} \mathrm{VO}_{2} \mathrm{~F}$ was ball-milled with carbon black (CB, acetylene black, Alfa Aesar) for $3 \mathrm{~h}$ at $300 \mathrm{rpm}$ to form a composite. The electrode slurry consisted of 70 wt $\% \mathrm{Li}_{2} \mathrm{VO}_{2} \mathrm{~F}, 20$ wt $\% \mathrm{CB}$, and $10 \mathrm{wt} \%$ polyvinylidene difluoride (PVdF) binder (Solvey 6050) mixed with $N$-methyl-2-pyrrolidone (Alfa Aesar, 99.5\%). The slurry was coated, by doctor blade, onto aluminum foil with a wet film thickness of $250 \mu \mathrm{m}$ and was subsequently dried in vacuum with a stepwise increasing temperature up to $120{ }^{\circ} \mathrm{C}$ for $12 \mathrm{~h}$. The resulting mass loading of $\mathrm{AM}$ was approximately $1.5 \mathrm{mg} \mathrm{cm}^{-2}$.

Electrochemical Methods. Pouch-type cells were prepared in an argon-filled glovebox $\left(\mathrm{O}_{2}<2 \mathrm{ppm}, \mathrm{H}_{2} \mathrm{O}<1 \mathrm{ppm}\right)$. Circular electrodes of $13 \mathrm{~mm}$ diameter were punched from the electrode sheets and thereafter stacked together with two layers of the Solupor separator (total separator thickness $20 \mu \mathrm{m}$ ) and a lithium foil (125 $\mu \mathrm{m}$ thick, Cyprus Foote Material) as the counter electrode. $1 \mathrm{M} \mathrm{LiPF}_{6}$ $(50 \mu \mathrm{L})$ in ethylene carbonate (EC)/dimethyl carbonate (DMC) 1:1 $\mathrm{v} / \mathrm{v}$, (Solvionic, 99.9\%) was used as the electrolyte and the pouches were sealed by a vacuum sealer. The cells were cycled on a Digatron BTS 600 galvanostat with current corresponding to a C-rate of $\mathrm{C} / 10$, based on the theoretical capacity for $\mathrm{Li}_{2} \mathrm{VO}_{2} \mathrm{~F}$ of $462 \mathrm{~mA} \mathrm{~h} \mathrm{~g}$. The cycling was performed at room temperature with the upper and lower cutoff voltages set to 4.1 and $1.3 \mathrm{~V}$ versus $\mathrm{Li} / \mathrm{Li}^{+}$, respectively. Seven $\mathrm{Li}_{2} \mathrm{VO}_{2} \mathrm{~F}$ electrodes with different cycling protocols were prepared for the study according to Table 1 . In the Results section, the abbreviated names will be used to refer to different samples.

Characterization. Cells were opened in an argon glovebox $\left(\mathrm{O}_{2}<\right.$ $2 \mathrm{ppm}, \mathrm{H}_{2} \mathrm{O}<1 \mathrm{ppm}$ ), carefully rinsed with DMC (Merck, $\geq 99 \%$ ) to remove electrolyte residues and subsequently mounted on sample holders with conductive carbon tape. For XAS measurements, $\mathrm{V}_{2} \mathrm{O}_{3}$ (Alfa Aesar, 99.7\%) and $\mathrm{V}_{2} \mathrm{O}_{5}$ (Alfa Aesar, 99.9\%) powders were pressed into conductive $\mathrm{Cu}$ tape and used as $\mathrm{V}^{3+}$ and $\mathrm{V}^{5+}$ references, respectively. Samples were transported to synchrotrons and transferred into the beamline end-stations without exposure to air. PES measurements were performed at the I09 beamline at Diamond Light Source, UK. ${ }^{61}$ Three different energies were used for each core level corresponding to $150 \mathrm{eV}$ kinetic energy, $450 \mathrm{eV}$ kinetic energy (soft $\mathrm{X}$-ray branch), and $4 \mathrm{keV}$ photon energy (hard X-ray branch). Hard $\mathrm{X}$-rays were monochromatized by a $\mathrm{Si}(111)$ double-crystal monochromator and soft X-rays by a plane grating monochromator using collimated light. A Scienta EW4000 high-voltage electron analyzer was used to record the spectra. The probing depth was estimated as 3 times the inelastic mean free path (IMFP) for each photon energy, corresponding to $95 \%$ of the total intensity stemming from this depth. Nevertheless, because the intensity function is exponentially decreasing, a large part of the signal still originates from the nearsurface/interphase layer even for more bulk sensitive measurements. ${ }^{62}$ Using IMFP values of polyethylene ${ }^{63}$ derived from the NIST database, ${ }^{64}$ the resulting probing depths were $2 \mathrm{~nm}(150 \mathrm{eV}), 5 \mathrm{~nm}$ $(450 \mathrm{eV})$, and $30 \mathrm{~nm}(4 \mathrm{keV})$. These values can be seen as an upper limit for the probing depths as they are mostly representative of the low-density surface layer, while for the denser AM, smaller probing depths would be expected. In this case, thickness estimation is only made for the interphase layer, and thus, polyethylene was chosen as a representative compound. XAS measurements were performed at the KMC-1 beamline at BESSY II, Germany. ${ }^{65}$ Spectra were recorded in the fluorescence yield mode using a Bruker XFlash 4010 detector.

Data Analysis. PES data analysis and curve-fitting were performed using Igor Pro 6.37 software. Curve-fitting of the acquired data was made to determine binding energies and areas of the peaks needed to fit the data, corresponding to different compounds present in the sample. To be able to compare the relative amount of different elements using different incoming photon energies, the photo- 
Table 1. Names, Abbreviations, and Cycling Protocols for Different Samples Used in the Study

\begin{tabular}{|c|c|c|c|c|c|c|c|}
\hline Sample & Pristine & $\begin{array}{c}\text { Delithiated } \\
1 / 2 \text { cycle }\end{array}$ & $\begin{array}{c}\text { Lithiated } \\
1 \text { cycle }\end{array}$ & $\begin{array}{c}\text { Delithiated } \\
41 / 2 \text { cycles }\end{array}$ & $\begin{array}{c}\text { Lithiated } \\
5 \text { cycles }\end{array}$ & $\begin{array}{c}\text { Delithiated } \\
491 / 2 \text { cycles }\end{array}$ & $\begin{array}{c}\text { Lithiated } \\
50 \text { cycles }\end{array}$ \\
\hline Abbreviation & P & D1 & L1 & D5 & L5 & D50 & L50 \\
\hline Cycling & None & $\begin{array}{c}\text { charged to } 4.1 \\
\text { V }\end{array}$ & $\begin{array}{c}\text { charged to } 4.1 \\
\text { V, discharged } \\
\text { to } 1.3 \mathrm{~V}\end{array}$ & $\begin{array}{c}4 \text { full cycles, } \\
\text { charged to } 4.1 \\
\text { V }\end{array}$ & 5 full cycles & $\begin{array}{c}49 \text { full cycles, } \\
\text { charged to } 4.1 \\
\text { V }\end{array}$ & \begin{tabular}{c}
50 full cycles \\
\hline
\end{tabular} \\
\hline
\end{tabular}

ionization cross section and also the incoming photon intensity need to be taken into account. The ratios of different materials can be calculated according to eq 1 .

$$
\frac{n_{i}}{n_{j}}=\frac{A_{i} I_{E_{i}} / \sigma_{i}}{A_{j} I_{E_{j}} / \sigma_{j}}
$$

where $A_{i, j}$ is the peak area of elements $i$ and $j, I_{E_{i, j}}$ is the relative incoming intensity for photon energy $E_{i, j}$, and $\sigma_{i, j}$ is the theoretical photoionization cross section for the relevant subshell of the same elements, as calculated according to work by Yeh and Lindau ${ }^{66}$ for soft X-ray energies and Scofield ${ }^{67}$ for hard X-ray energies. The cross section for a subshell depends only on the photon energy and can thus be used for quantification of different elements in a sample, but care should be taken to include any shake-up features if present in the spectra. ${ }^{68-70}$ The spectrometer used also affects the intensity, and no correction is performed to take into account the dependence on the angle between the polarization vector and the photoelectron direction for $\mathrm{p}$ orbitals. Additionally, it should be noted that generally, the relative amount of compounds that are solvable in DMC may be slightly reduced as a result of the washing procedure. ${ }^{71,72}$ Because of these various uncertainties, relative changes between samples rather than absolute values are considered when evaluating the spectra.

The PES data were normalized in intensity to the most intense peak of each spectrum and energy calibrated by fixing the hydrocarbon peak $(\mathrm{C}-\mathrm{H})$ at $285 \mathrm{eV}$. To make a reasonable fit of the different spectra, some peak parameters were locked. In the $\mathrm{C} 1 \mathrm{~s}$ spectra, the PVdF peaks were fixed at a distance of $4.46 \mathrm{eV}$ from each other according to peak parameters established by Beamson and Briggs. ${ }^{73}$ Because of the overlap in binding energy between $\mathrm{CF}_{2}$ and $\mathrm{CO}_{3}$, the intensity ratio of PVdF and $\mathrm{CB}$ was also fixed according to the ratio in the pristine sample. P 2p spectra were fitted using a spinorbit split according to Moulder and Chastain ${ }^{68}$ while for V $2 \mathrm{p}$ spectra, work by Biesinger et al. ${ }^{74}$ was used to determine spin-orbit split and oxidation states. For samples with a weak metal oxide (MO) peak, the distance between different oxygen peaks was set to match those of previous samples with a clearly visible MO peak. For several elements, compounds with similar binding energies were expected to be present in the sample, such as $\mathrm{Li}_{2} \mathrm{VO}_{2} \mathrm{~F}$ and $\mathrm{LiF}$ in $\mathrm{F} 1 \mathrm{~s}$ spectra and different $\mathrm{PF}_{x}^{-}$variations in the $\mathrm{P} 2 \mathrm{p}$ spectra. These compounds are fitted with only one peak because of limited resolution of spectra, but a change of relative ratios can sometimes be seen as a binding energy shift for these peaks. This will be further discussed in the Results section.

XAS data are normalized and flattened using Athena software to facilitate comparison between samples. Because of an unstable beam position, $I_{0}$ varied significantly during measurements causing noisy data. Therefore, a smoothing of the data was performed in Athena using boxcar average with a Kernel size of 11. Energy calibration of the XAS data was performed using the energy shift needed to set the binding energy of $\mathrm{Au} 4 \mathrm{f}_{7 / 2}$ at $84 \mathrm{eV}$. The edge position was determined using the inflection point of the smoothed data.

Illustrations of the material structure were made using VESTA 3 software. $^{75}$

\section{RESULTS}

In the Results section, a short note is made concerning the electrochemical performance, confirming already published results showing a severe capacity degradation upon cycling (for a more in depth analysis, see earlier work $\left.{ }^{12,18}\right)$. In the second and main part, the spectroscopic analysis is presented, and we suggest possible mechanisms behind the capacity fading in $\mathrm{Li}_{2} \mathrm{VO}_{2} \mathrm{~F}$.

Electrochemical Performance. Through electrochemical measurements, an initial capacity of around $320 \mathrm{~mA} \mathrm{~h} \mathrm{~g}^{-1}$ for $\mathrm{Li}_{2} \mathrm{VO}_{2} \mathrm{~F}$ cathodes and a rapid fading of capacity on further cycling are observed, as seen in Figure 2. The experimental

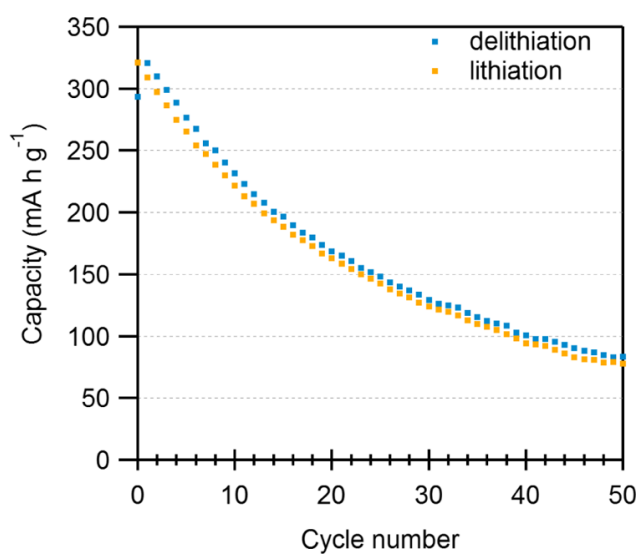

Figure 2. Capacity as a function of the cycle number for $\mathrm{Li}_{2} \mathrm{VO}_{2} \mathrm{~F}$ electrodes cycled vs Li-metal in the $1 \mathrm{M}$ LiPF6 EC/DEC 1:1 v/v electrolyte. A C-rate of C/10, based on the theoretical capacity of 462 $\mathrm{mA} \mathrm{h} \mathrm{g}{ }^{-1}$, is used and the voltage window used is 1.3 to $4.1 \mathrm{~V}$ vs $\mathrm{Li}$ / $\mathrm{Li}^{+}$.

capacity corresponds to approximately $70 \%$ of the theoretical value of $462 \mathrm{~mA} \mathrm{~h} \mathrm{~g}^{-1}$, assuming full delithiation and oxidation of vanadium from $3+$ to $5+$. These results are in good agreement with previous studies using the same C-rate, showing that not all of lithium can be extracted from the disordered rock-salt material without a phase transition to the rhombohedral structure of $\mathrm{VO}_{2} \mathrm{~F}^{12,18,76-78}$ and thus, the fully delithiated state is never reached. ${ }^{78}$

In the first cycle, less lithium is extracted during charge than inserted during discharge. This indicates lithium deficiency in the pristine sample, as previously suggested by Wang et al. ${ }^{18}$ In all the following cycles, a little more lithium can be extracted than what was previously inserted, and upon every re-lithiation, the capacity decreases. After 50 cycles, the remaining capacity is approximately $25 \%$ of the original value.

X-ray Spectroscopic Elemental Specific Analysis. In this section, the oxidation state of vanadium is studied by combining PES and XAS results, resulting in clear evidence that vanadium is no longer redox-active after 50 full charge/ discharge cycles and ends up in a highly oxidized state $\left(\mathrm{V}^{5+}\right)$. The degradation begins at the $\mathrm{Li}_{2} \mathrm{VO}_{2} \mathrm{~F}$ particle surface and extends further into the bulk with continued cycling. The 


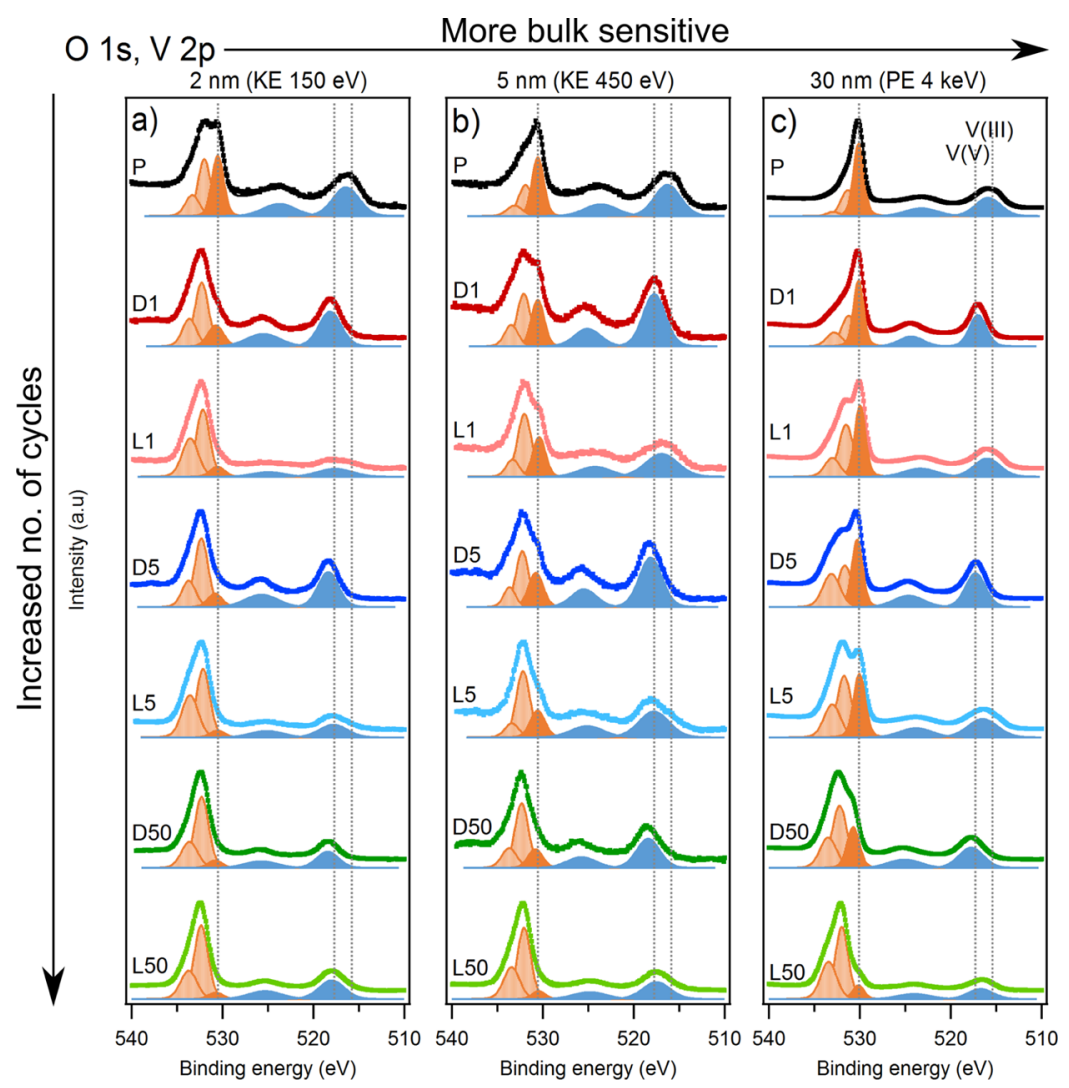

Figure 3. PE spectra of $\mathrm{O} 1 \mathrm{~s}, \mathrm{~V} 2 \mathrm{p}$ for all samples using three different photon energies probing the interphase layer (a), near-surface (b), and outer bulk (c). Intensity normalized spectra are shown together with corresponding curve fitting. Blue peaks indicate vanadium contributions while dark orange corresponds to the MO and light orange to surface oxygen compounds. References corresponding to $\mathrm{V}(\mathrm{III})$ and $\mathrm{V}(\mathrm{V})$ are indicated by labels. $^{74}$

gradual loss of redox-active vanadium is consistent with the capacity fade as shown in Figure 2.

Redox Activity of $\mathrm{Li}_{2} \mathrm{VO}_{2} \mathrm{~F}$. In Figure 3, the PE spectra of $\mathrm{O} 1 \mathrm{~s}$ and V $2 \mathrm{p}$ are shown for three different probing depths, together with spectral peak fitting. Spectra obtained using higher photon energies give relatively more information from

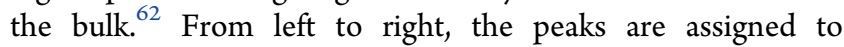
carboxyl/hydroxyl groups (light orange, $\sim 534 \mathrm{eV}$ ), carbonates (light orange, $\sim 532 \mathrm{eV}$ ), MO (dark orange, $\sim 530.5 \mathrm{eV}$ ), and vanadium that is detected with a spin orbit splitting of $7.33 \mathrm{eV}$ at $\sim 517$ and $\sim 524 \mathrm{eV}$ (blue peaks). ${ }^{74}$ The relative binding energy positions between the MO peak and the $\mathrm{V} 2 \mathrm{p}_{3 / 2}$ peak are presented in Table 2 . These values are indicative of the vanadium oxidation state, where a larger energy difference corresponds to a lower oxidation state. ${ }^{74}$

Following the oxidation state of vanadium, it is clear that the material degrades by converting to new nonredox-active phases containing fully oxidized $\mathrm{V}^{5+}$ upon cycling. From Table 2, it can be seen that the interphase layer measurements show highly oxidized $\mathrm{V}$ already after the first full cycle, while the AM at the near-surface and outer bulk is (partly) redox-active after 1 and 5 cycles, respectively. After 50 cycles, no vanadium in the region probed by PES displays any redox activity. This shows that the degradation starts at the surface and gradually moves into the bulk.

In detail, the pristine $\mathrm{Li}_{2} \mathrm{VO}_{2} \mathrm{~F}$ material shows an average vanadium oxidation state close to $4+$, instead of the expected $3+$ from the structural formula. This can be a result of the pristine $\mathrm{Li}_{2} \mathrm{VO}_{2} \mathrm{~F}$ material being slightly lithium-deficient, other
Table 2. Binding Energy Difference between the MO and Vanadium $2 p_{3 / 2}$ Peaks for Different Samples and Probing Depths $^{a}$

$\begin{array}{cccc}\text { sample } & \Delta E(\mathrm{eV}), 2 \mathrm{~nm} & \Delta E(\mathrm{eV}), 5 \mathrm{~nm} & \Delta E(\mathrm{eV}), 30 \mathrm{~nm} \\ \text { P } & 14.1 & 14.2 & 14.3 \\ \text { D1 } & 12.6 & 12.8 & 13.1 \\ \text { L1 } & 12.9 & 13.5 & 14.0 \\ \text { D5 } & 12.5 & 12.6 & 13.0 \\ \text { L5 } & 12.7 & 12.8 & 13.6 \\ \text { D50 } & 12.4 & 12.4 & 13.0 \\ \text { L50 } & 12.8 & 12.6 & 12.9\end{array}$

${ }^{a}$ Corresponding values for $\mathrm{V}^{3+}, \mathrm{V}^{4+}$, and $\mathrm{V}^{5+}$ references are $14.7,14.2$, and $12.8 \mathrm{eV}$, respectively. ${ }^{74}$

vanadium phases being present in the material, or the surface being somewhat oxidized. After first delithiation (sample D1), the most surface-sensitive measurement (Figure 3a) shows an energy split closely corresponding to vanadium in the fully oxidized $\mathrm{V}^{5+}$ state, while the outer bulk measurement (Figure 3c) has a slightly larger energy difference, indicating a lower oxidation state of vanadium. This implies an incomplete delithiation of the outer bulk giving contribution to the spectra that results in a peak shift toward lower binding energies, consistent with the structural instability of the fully delithiated material. $^{12,18}$

Upon further cycling, the difference in the oxidation state between delithiated and lithiated samples is less pronounced. This is especially clear at the surface where vanadium remains fully oxidized after 5 cycles. Vanadium still shows redox activity 
in the outer bulk after 5 cycles, which subsequently diminishes significantly after 50 cycles.

When the $\mathrm{Li}_{2} \mathrm{VO}_{2} \mathrm{~F}$ cathode is lithiated (sample $\mathrm{L} 1$ ), the vanadium peak is significantly broadened (Figure $3 a-c$ ), which would be expected from a sample that contains a mixture of oxidation states between $3+$ and $5+$. Such mixing implies that vanadium oxidation is not entirely reversible, which serves as one reason for the capacity fading as seen in electrochemical cycling. The decrease of the vanadium oxidation state with probing depth shows that it is predominantly the near-surface of the $\mathrm{Li}_{2} \mathrm{VO}_{2} \mathrm{~F}$ particle that cannot be relithiated. Upon further cycling, the difference in the oxidation state between delithiated and lithiated samples diminishes also for the outer bulk, implying that the irreversible degradation of the material starts at the surface of the $\mathrm{Li}_{2} \mathrm{VO}_{2} \mathrm{~F}$ particle already during the first cycle and spreads in toward the bulk with prolonged cycling.

It can also be noted that the energy split between the MO and vanadium peaks is slightly smaller than expected for $\mathrm{V}^{5+}$ in $\mathrm{V}_{2} \mathrm{O}_{5}$ for several of the two more surface-sensitive measurements. Vanadium coordinated by more electronegative elements, such as fluorine, could explain the increased binding energy, ${ }^{79}$ but the $\mathrm{MO}$ intensity is weak for these samples giving a degree of uncertainty for the binding energy position.

Shifting focus to the MO peak (dark orange), broadening can be seen at the surface and after cycling (from $\sim 1.2$ to $\sim 1.7$ $\mathrm{eV}$ fwhm) that can be indicative of an oxygen redox process, resulting in different net charges on the oxygen atoms and a following spread of binding energies. ${ }^{80-82}$ Charge compensation by oxygen will result in a highly reactive material that in turn can cause formation of new MO environments contributing to broader oxide peaks. Because oxygen redox has been found to be related to material degradation of other Li-rich materials, this can also be a reason for the capacity fading in $\mathrm{Li}_{2} \mathrm{VO}_{2} \mathrm{~F}$.

Fluorescent yield XAS measurements were performed to verify the change in the redox state of vanadium in the bulk upon cycling. Figure 4 shows the vanadium K-edge of the $\mathrm{Li}_{2} \mathrm{VO}_{2} \mathrm{~F}$ material and Table 3 shows the corresponding edge positions. Generally, the main edge shifts to higher energies when the oxidation state of vanadium is increased. ${ }^{83}$ In

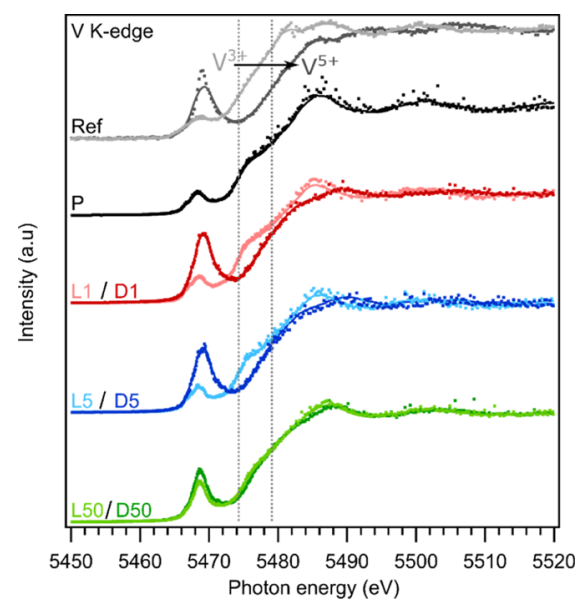

Figure 4. Vanadium K-edge XANES for reference powders (gray), a pristine $\mathrm{Li}_{2} \mathrm{VO}_{2} \mathrm{~F}$ electrode (black) and electrodes cycled $1-50$ cycles. Darker colors represent delithiated (more oxidized) samples. Data points are shown together with smoothed curves (solid lines). addition, a more pronounced pre-edge is expected for the $\mathrm{V}^{5+}$ state, as shown by the two reference samples, $\mathrm{V}_{2} \mathrm{O}_{3}$ and $\mathrm{V}_{2} \mathrm{O}_{5}$, for the $\mathrm{V}^{3+}$ state and $\mathrm{V}^{5+}$ state, respectively. It has previously been shown ${ }^{83}$ that $\mathrm{V}^{4+}$ spectra present a similar pre-edge feature as seen in the $\mathrm{V}^{5+}$ state but with less intensity and shifted to lower energy.

Initially during cycling (L1/D1, L5/D5), vanadium shows a bulk redox activity as expected with delithiated samples shifted to higher energies and with more pronounced pre-edges compared to lithiated samples. On the other hand, the curves for the D50 and L50 samples are very similar and show that even in the bulk, most of the vanadium is no longer part of the redox activity after 50 cycles.

Looking closer at the XAS spectra of the pristine L1 and L5 samples, these show large similarities to the $\mathrm{V}^{3+}$ reference, with the exception of a knee around $5475 \mathrm{eV}$, where the inclination of the main edge changes. The change in slope can be explained by a mix of different oxidation states, where the first part of the main edge corresponds to $\mathrm{V}$ in the $3+$ state and the second part to $\mathrm{V}$ in the 4+ or 5+ state. This mix is seen already for the pristine sample, supporting that the material contains regions with vanadium in different oxidation states, which could be expected depending on what anions (oxide and/or fluoride) surround vanadium in the disordered material.

The spectra of the delithiated samples show mostly similarities to the $\mathrm{V}^{5+}$ reference with a clearly pronounced pre-edge, but here, a small knee is also seen, especially for the samples cycled 50 times. The XAS results support the intermixing of oxidation states as seen by PES and further confirm that all of the material is never fully lithiated to the $3+$ state nor fully delithiated to a complete 5+ state.

$\mathrm{Li}_{2} \mathrm{VO}_{2} \mathrm{~F}$ Composition. To evaluate to what extent the loss of redox activity is coupled to a breakdown of the AM, the relative amount of $\mathrm{V}$ and $\mathrm{MO}$ is estimated using eq 1 and presented in Table 4. According to the structural formula of $\mathrm{Li}_{2} \mathrm{VO}_{2} \mathrm{~F}$, the expected ratio is $1: 2$, which is also the calculated value for the surface sensitive measurements of the pristine sample, while a comparatively higher amount of oxygen is found in the outer bulk of the material. Upon cycling, the ratio is increased during delithiation and thereafter reversed during lithiation, with the largest recovery for the first cycle and the outer bulk measurement. The ratio is consistently higher, closer to the surface, and is also increasing with cycling.

An increase in the $\mathrm{V} / \mathrm{MO}$ ratio can originate from oxygen redox, a conversion of MO to other oxygen compounds or alternatively by vanadium dissolution followed by detrimental reactions where vanadium reacts with the electrolyte and is incorporated in the interphase layer. The lowered ratio upon lithiation could then be explained by a partially reversible oxygen redox process or by dissolution of the interphase layer. These factors and how they can be combined to explain the changes in $\mathrm{V} / \mathrm{MO}$ ratio are further deliberated in the discussion, after analyzing the interphase layer evolution in the next section.

Oxygen redox has been seen for other Li-rich disordered rock salts at potentials around $4 \mathrm{~V}$ versus $\mathrm{Li} / \mathrm{Li}^{+}, 30,84,85$ and in other PES studies, oxidized $\mathrm{O}^{n-}$ has been identified at binding energies approximately $1 \mathrm{eV}$ higher than $\mathrm{O}^{2-} \cdot{ }^{8-82}$ In this study, this peak has not been resolved because of the difficulty of separating it from the overlapping carbonate peak with good certainty. Nevertheless, an oxygen redox activity could explain the peak broadening and the relatively higher binding energy of the MO peak measured at the surface of the material. A 
Table 3. Energy Positions of the Main Vanadium K-Edge for All Samples Calculated from the Inflection Point of the Smoothed Out Data

\begin{tabular}{|c|c|c|c|c|c|c|c|c|c|}
\hline sample & $\mathrm{P}$ & D1 & L1 & D5 & L5 & D50 & L50 & $\mathrm{V}_{2} \mathrm{O}_{3}$ & $\mathrm{~V}_{2} \mathrm{O}_{5}$ \\
\hline edge position $(\mathrm{eV})$ & 5474.4 & 5476.9 & 5474.0 & 5477.3 & 5474.3 & 5475.9 & 5475.2 & 5474.3 & 5479.1 \\
\hline
\end{tabular}

Table 4. Relative Amount of Vanadium Compared to MO (V:MO) Estimated from PES Data Using Eq 1

\begin{tabular}{lccc} 
& \multicolumn{3}{c}{$\mathrm{V} / \mathrm{MO}$} \\
\cline { 2 - 4 } P & $2 \mathrm{~nm}$ & $5 \mathrm{~nm}$ & $30 \mathrm{~nm}$ \\
D1 & $1: 2.16$ & $1: 1.92$ & $1: 3.05$ \\
L1 & $1: 0.68$ & $1: 1.13$ & $1: 2.29$ \\
D5 & $1: 1.25$ & $1: 1.55$ & $1: 3.00$ \\
L5 & $1: 0.83$ & $1: 1.01$ & $1: 1.99$ \\
D50 & $1: 0.91$ & $1: 1.17$ & $1: 2.55$ \\
L50 & $1: 0.69$ & $1: 0.93$ & $1: 1.86$ \\
\hline
\end{tabular}

following reduction of oxygen back to $\mathrm{O}^{2-}$ would explain the regained $\mathrm{MO}$ intensity upon lithiation.

The lower ratio of 1:3 V/MO obtained for the outer bulk of the pristine sample corresponds to a structure where only oxygen would be present at the anion sites around vanadium. Because the material is a disordered rock salt, the distribution of anions is random, and it is reasonable to believe that this would be the case for some vanadium atoms. However, the higher MO content compared to the structural formula could be an indication of vanadium, preferably forming $\mathrm{V}-\mathrm{O}$ bonds while $\mathrm{Li}$ is more likely to bond to $\mathrm{F}$. This is in agreement with density functional theory (DFT) calculations performed by Richards et al., ${ }^{86}$ showing that when fluorine is incorporated in Li-ion cathode materials, $\mathrm{F}$ is mostly located in lithium-rich regions because of the comparably much higher formation energy of TM-F bonds. An overrepresentation of oxygen around vanadium could also explain the higher oxidation state of $\mathrm{V}$ because the presence of $\mathrm{Li}_{2} \mathrm{VO}_{3}$ sites would give vanadium in the $4+$ state.

The spectra probing the interphase layer of the cycled samples always show much higher vanadium to oxygen ratio than expected. Although higher, the ratio for the delithiated samples appears to be rather stable upon increased cycling. Following the lithiated samples instead, the ratio increases with increasing cycle number, suggesting that there is a loss of MO in the material upon cycling. However, the relative ratio of $\mathrm{V} /$ MO for the lithiated samples is initially lower than that for the previous delithated state, indicating a small regain of $\mathrm{MO}$ during lithiation. ${ }^{80-82}$ After 50 cycles, the MO content is lower in the lithiated state, likely related to the buildup of an interphase layer and possible vanadium dissolution.

The trend observed for the $\mathrm{V} / \mathrm{MO}$ ratio in the outer bulk is similar to that for the near-surface. The analysis strongly indicates the conversion of lattice oxygen, leading to the

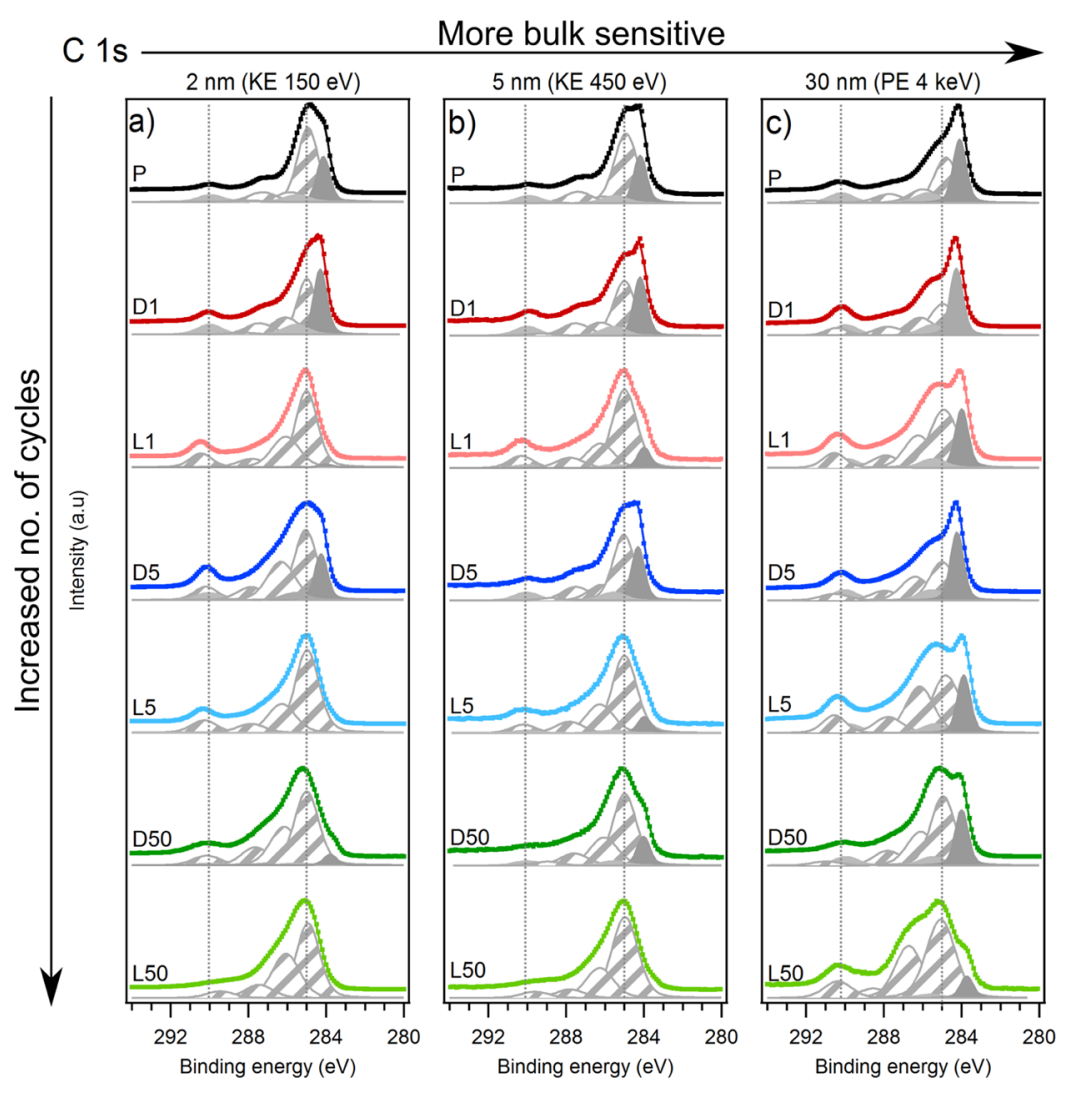

Figure 5. PE spectra of the $\mathrm{C} 1 \mathrm{~s}$ core level for all samples using three different photon energies probing the interphase layer (a), near-surface (b), and outer bulk (c). Intensity normalized spectra are shown together with corresponding curve fitting. The dark gray peak stems from $\mathrm{CB}$, light gray from the PVdF binder, and striped peaks from surface compounds. 


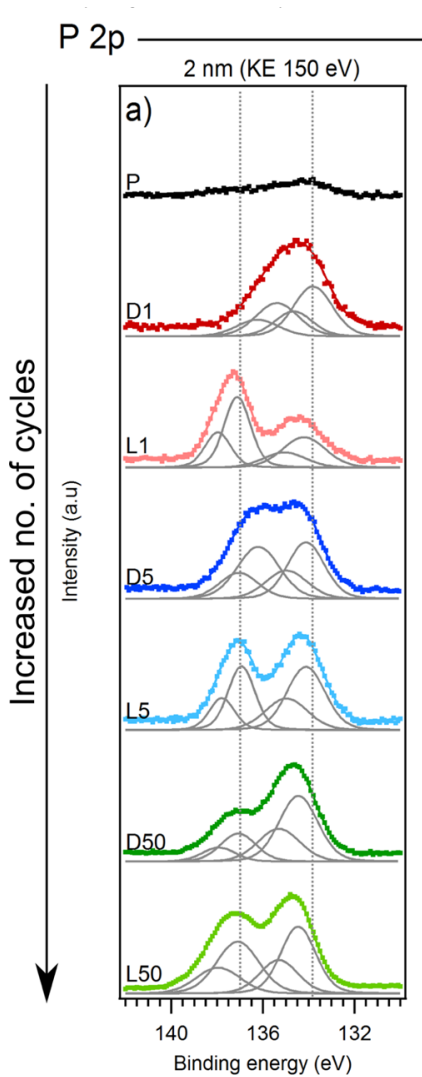

More bulk sensitive
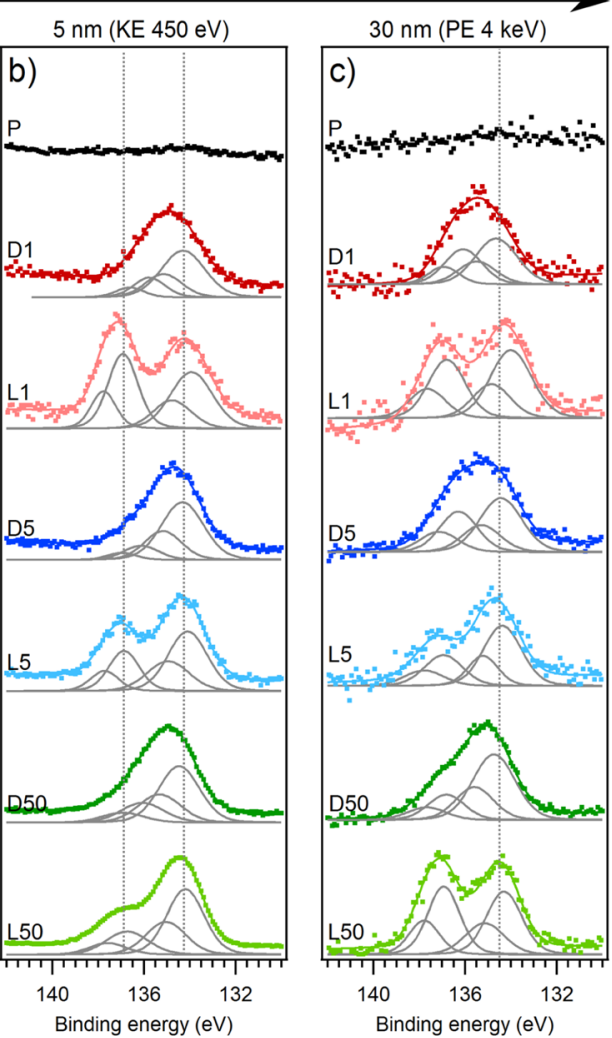

Figure 6. PE spectra of the P $2 p$ core level for all samples using three different photon energies probing the interphase layer (a), near-surface (b), and outer bulk (c). Intensity normalized spectra are shown together with corresponding curve fitting.

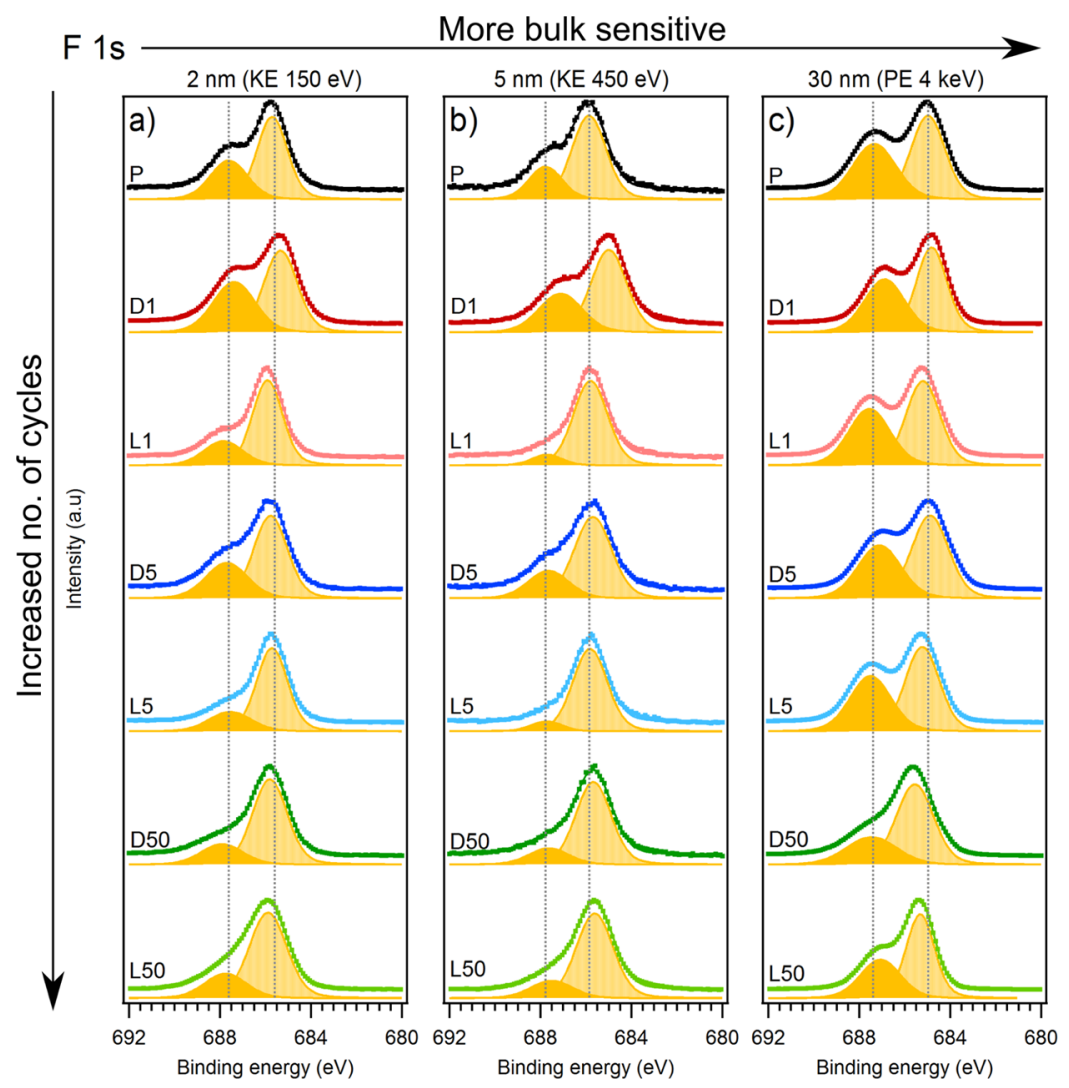

Figure 7. PE spectra of the F 1s core level for all samples using three different photon energies probing the interphase layer (a), near-surface (b), and outer bulk (c). Intensity normalized spectra are shown together with corresponding curve fitting. 
degradation of $\mathrm{Li}_{2} \mathrm{VO}_{2} \mathrm{~F}$ and likely the formation of new vanadium phases starting at the surface.

Stability and Composition of the Interphase Layer. An interphase layer is commonly found on the cathode surface after cycling. ${ }^{43,44}$ The stability and composition of this interphase layer affects the cycling performance and may therefore be evaluated to further understand the capacity fading of $\mathrm{Li}_{2} \mathrm{VO}_{2} \mathrm{~F}$. C 1s, P 2p, and $\mathrm{F}$ 1s spectra are presented in Figures 5-7, and an overview of the relative amounts of different elements estimated using eq $\mathrm{S} 1$ is presented in the Supporting Information.

As a first remark, it is clear from the PE spectra that a thickening interphase layer is built up during cycling. This is seen from the decreased intensity of the peaks stemming from the bulk material, such as CB (dark grey) in the C 1s spectra (Figure 5) and the MO peak (dark orange) in the O 1s spectra (Figure 3). The interphase layer is always seen to be thicker on the lithiated samples compared to the corresponding delithiated sample. This clearly shows that the degradation reactions building up the interphase layer occur mainly during lithiation.

In more detail, peak fitting of the carbon spectra (Figure 5) demonstrates that the carbon signal contains contributions from both common surface species (striped peaks) such as hydrocarbons (at $285 \mathrm{eV}$ ) and carbon bonded to one, two, or three oxygens (at $\sim 286.5,288$ and $290 \mathrm{eV}$, respectively), as well as peaks associated with the additives CB (dark grey at $\sim 284 \mathrm{eV}$ ) and the PVdF binder (two light grey peaks at 286 and $290 \mathrm{eV}$ ) used in the electrode material.

The first delithiated sample, D1, is seen to be very similar to the pristine sample, showing only minor changes in the $\mathrm{C} 1 \mathrm{~s}$ spectra. Upon first lithiation, however, the two most surfacesensitive spectra clearly indicate the formation of an interphase layer, as seen by the disappearance or decreased intensity of the $C B$ signal together with a strong relative increase of the hydrocarbon peak. It is furthermore clear from the $\mathrm{CB}$ intensity that under continuous cycling, the interphase is partially stripped during delithiation and reformed during following lithiation. As the interphase layer grows thicker, the $\mathrm{CB}$ signal diminishes and an increase of different $\mathrm{C}-\mathrm{O}$ peaks is seen, consistent with these compounds being common battery electrolyte degradation products. ${ }^{87-90}$ This implies that there is a continuous consumption of the electrolyte during lithiation of $\mathrm{Li}_{2} \mathrm{VO}_{2} \mathrm{~F}$ and shows that there is a lack of a sufficiently stable surface layer to protect the AM from further degradation. Thus, stabilization of either the particle surface or the surface layer is necessary to improve the long-term stability of the $\mathrm{Li}_{2} \mathrm{VO}_{2} \mathrm{~F}$ cathode material.

The CB peak is visible in all measurements of delithiated samples, and thus, the interphase layer thickness is estimated to be thinner than the most shallow probing depth of $2 \mathrm{~nm}$. On the lithiated samples, the interphase is thicker, but still less than $5 \mathrm{~nm}$ after 5 cycles while after 50 cycles, the bulk $\mathrm{CB}$ can only be seen with a probing depth of $30 \mathrm{~nm}$. After determining that $\mathrm{CB}$ is no longer visible in the most surface-sensitive measurements of the lithiated samples, it is interesting to note that both vanadium and MO peaks are still visible for the same samples. This supports dissolution and incorporation of vanadium oxide in the interphase layer but can also be a result of the interphase layer predominantly being deposited on the $\mathrm{CB}$ additive.

From the phosphorus spectra (Figure 6), we can clearly determine that degradation of the $\mathrm{LiPF}_{6}$ salt occurs upon cycling because all cycled samples show the presence of different $P 2 p$ environments. It is also seen that this degradation continues during cycling because the $\mathrm{P} 2 \mathrm{p}$ signal consistently increases up to 50 cycles.

As expected, no phosphorous is detected on the pristine sample (black dots). In the spectra for cycled electrodes, different environments each consisting of two spin orbit split peaks at a distance of $0.84 \mathrm{eV}^{68}$ can be identified. The lower binding energy feature corresponds well with expected binding energies of phosphates or $\mathrm{PO}_{x} \mathrm{~F}_{y}$ compounds. ${ }^{68,91}$ The higher binding energy feature stems from $\mathrm{PF}_{x}{ }^{-}$ions, where the intact $\mathrm{PF}_{6}{ }^{-}$ion is normally detected at a binding energy of $\sim 137 \mathrm{eV}$, and decomposition products with a lower fluorine content $\left(\mathrm{PF}_{x}{ }^{-}, x \leq 5\right)$ has been found to be $\sim 1 \mathrm{eV}$ lower. ${ }^{90,92,93}$ The decomposed salt ions can be seen on the delithiated samples, but the $\mathrm{PF}_{x}^{-}$peak has not been separated from the intact $\mathrm{PF}_{6}{ }^{-}$ peaks as the resolution does not allow this to be done with precision. Instead, the binding energy shift of the high binding energy phosphorus feature can be seen as a measure of the amount of intact salt that remains on the sample. Because samples are washed before measurement, only small amounts of $\mathrm{PF}_{6}{ }^{-}$may be expected at the surface, for a sample with minimal interphase layer, and thus, the dominance of low binding energy compounds for the D1 and D5 samples is consistent with that expected. Still, intact salt may be expected to reside within the composite electrode, which may explain the relative increase of $\mathrm{PF}_{6}^{-}$in the most bulk-sensitive measurement of the delithiated samples. The existence of the low-energy P $2 \mathrm{p}$ peaks suggests that salt degradation occurs already during first delithiation and that the decomposition products are not soluble but remain at the surface of the particles.

For samples cycled 50 times, the peak associated with the electrolyte salt is seen to be at high binding energies, corresponding to more intact salt at the sample surface. The phosphate peak at $134.5 \mathrm{eV}$ is also clearly visible. This fits with the model where $\mathrm{PF}_{6}^{-}$residues remain within a deposited interphase layer (and is not easily washed off) together with the salt decomposition products. The relative amount of phosphorous (see the Supporting Information) increases with cycling and is generally higher on lithiated samples, consistent with the presence of a thicker interphase layer on these samples. The largest amount of decomposed salt (peak at $134.5 \mathrm{eV}$ ) is found at the near-surface measurement, indicating that there is a greater buildup of salt decomposition products close to the AM surface, while other species continue to be deposited in outer layers.

In the fluorine spectra (Figure 7), two peaks are fitted, associated with two different F-containing compounds. Generally, covalently bonded fluorine is found at higher binding energies $(\sim 687-688 \mathrm{eV})$, where we expect the PVdF binder or salt residues and degradation products of the $\mathrm{PF}_{6}{ }^{-}$ ion. At lower binding energies $(\sim 685 \mathrm{eV})$, ionic fluoride compounds such as $\mathrm{LiF}$ and the $\mathrm{AM} \mathrm{Li}_{2} \mathrm{VO}_{2} \mathrm{~F}$ are expected.

For the most bulk-sensitive measurements (Figure 7c) and particularly the pristine sample, the signal is dominated by PVdF (darker peak) and $\mathrm{Li}_{2} \mathrm{VO}_{2} \mathrm{~F}$ (lighter peak). For the middle probing depth (Figure $7 \mathrm{~b}$ ), the relative intensity of ionic fluorine is higher, which is explained by $\mathrm{LiF}$ at the nearsurface. $\mathrm{LiF}$ is also likely to form upon degradation of the salt, which explains the increased intensity of the ionic peak with cycling. This is also supported by the small shift in binding energy of the ionic peak toward higher energies $(\sim 0.8 \mathrm{eV}$ 

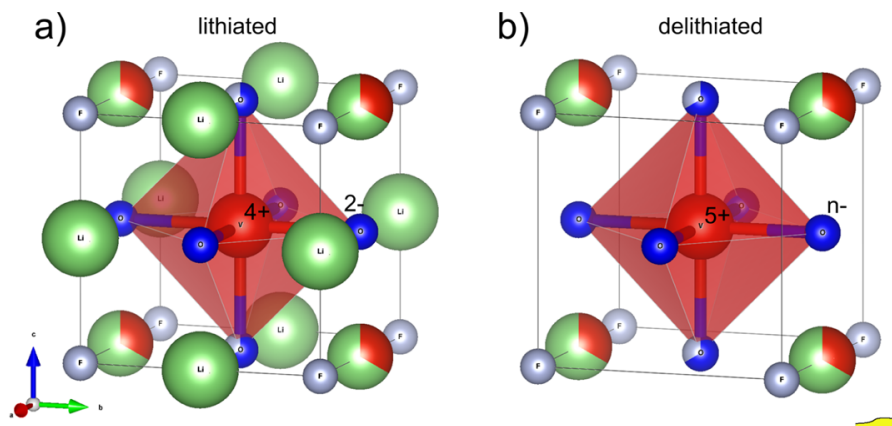

c)

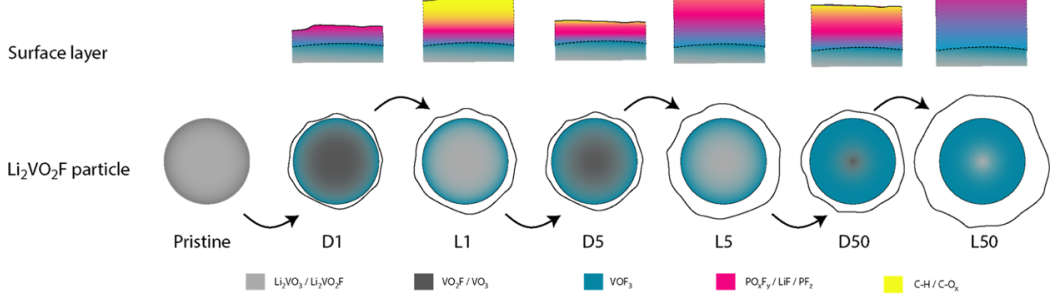

Figure 8. (a) Graphical illustration using VESTA 3 software $^{75}$ of a lithiated unit cell where oxygen preferably surrounds vanadium and fluorine preferably surrounds lithium, giving vanadium in the $4+$ state and oxygen in the $2-$ and (b) delithiated unit cell with vanadium in the $5+$ state and oxygen partially oxidized to $\mathrm{O}^{n-}$. (c) Schematic illustration of the redox reactions and degradation processes occurring in $\mathrm{Li}_{2} \mathrm{VO}_{2} \mathrm{~F}$ during $c y c l i n g$.

higher than for the outer bulk) because $\mathrm{LiF}$ is expected at slightly higher binding energy than $\mathrm{Li}_{2} \mathrm{VO}_{2} \mathrm{~F}$ according to DFT simulations (see the Supporting Information). For the most surface-sensitive measurements (Figure $7 \mathrm{a}$ ), the intensity of the organic peak is again relatively higher, especially for lithiated samples. This is explained by salt residues in the interphase layer, as seen also in the P 2 p spectra.

The lithium spectra (see the Supporting Information) only contain one main peak at a binding energy corresponding to ionic lithium $(\sim 56 \mathrm{eV})$. This feature includes contributions from residual salt, $\mathrm{LiF}$ and other lithium salts as well as the $\mathrm{AM}$ $\mathrm{Li}_{2} \mathrm{VO}_{2} \mathrm{~F}$. The lithium content varies during cycling (seen for all probing depths), with higher values for the lithiated samples, which is in good agreement with the AM being lithiated. Some lithium is also found in delithiated samples, suggesting that not all of lithium is extracted from the material and/or that other lithium compounds such as LiF that cannot be delithiated at these potentials ${ }^{94}$ are present already upon first delithiation. For the delithiated samples, both $\mathrm{Li}$ and ionic $\mathrm{F}$ are seen in greater quantities at the near-surface, indicating an accumulation of inorganic species in this region.

\section{DISCUSSION}

The changes in the $\mathrm{V} / \mathrm{MO}$ ratio seen by the spectroscopic results could, as previously mentioned, either be explained by a redox/conversion of lattice $\mathrm{O}^{2-}$ or by the buildup and dissolution of an interphase layer containing vanadium. Based on the PES results, we believe that both contribute, and a schematic illustration of our interpretation is presented in Figure 8c.

First, it is clear that the interphase is built up on first lithiation, while the $\mathrm{V} / \mathrm{MO}$ ratio is increasing already on first delithiation, before an interphase layer has been detected. With continuous cycling, the PES data show a gradual buildup of a thickening interphase layer containing highly oxidized, nonredox active vanadium compounds in addition to other common electrolyte degradation products. Because the interphase is built up during lithiation and partially stripped during delithiation, this is expected to result in higher V/MO ratios on lithiated samples compared to delithiated samples. However, for samples cycled 1 or 5 times, the opposite is true, with an increased ratio for delithiated samples and a following recovery upon lithiation. In our opinion, this can only be explained by an oxygen redox process that is partially reversible.

Second, if the oxygen redox process was entirely reversible, the $\mathrm{V} / \mathrm{MO}$ ratio would return to its original value upon lithiation. This is not the case, and instead, a continuous increase is seen upon extended cycling (comparing L1, L5 and L50). Because oxidized oxygen is known to be highly reactive, we believe that some of $\mathrm{O}^{n-}$ reacts irreversibly with the electrolyte upon lithiation. This results in the formation of an interphase layer, even at the relatively high potentials used $(>1.3 \mathrm{~V})$ where electrolytes are normally stable. A partially reversible and partially irreversible oxygen redox resulting in material degradation where new vanadium compounds are formed at the electrode/electrolyte interface can thus explain all the changes seen in the V/MO ratio.

The electrochemical results show that the capacity is always lower during lithiation than previous delithiation. These results support that material degradation occurs upon cycling, preventing the material from being reversibly lithiated. Based on the complete analysis, we therefore propose that the degradation of the material occurs upon deep delithiation and is coupled to an oxygen redox process. This model builds on the PES and XAS data indicating mixed phases in the material and on the hypothesis that the material contains a mixture of specifically $\mathrm{Li}_{2} \mathrm{VO}_{2} \mathrm{~F}$, oxygen excess $\mathrm{Li}_{2} \mathrm{VO}_{3}$ sites, and also $\mathrm{LiF}$ regions.

If there is a preference of oxygen surrounding vanadium while fluorine particularly is found around lithium, up to $75 \%$ of vanadium can be in a $\mathrm{Li}_{2} \mathrm{VO}_{3}$ environment while 
maintaining the correct stoichiometric ratio, as illustrated in Figure 8a. Vanadium present in these oxygen-rich coordinating sites would be in the $4+$ state when fully lithiated. This would suggest a short-range order in the material that is hidden in diffraction, as recently discovered as a possibility by Ji et al., ${ }^{95}$ but further structural analysis would be necessary to confirm this.

Upon delithiation, the redox couple $\mathrm{V}^{4+} / \mathrm{V}^{5+}$ can compensate for one extracted lithium ion, but any further delithiation from these $\mathrm{Li}_{2} \mathrm{VO}_{3}$ sites would need to be compensated by partial oxidation of $\mathrm{O}$, illustrated in Figure $8 \mathrm{~b}$. The oxygen redox activity is also supported by the excess capacity measured compared to the change in oxidation state of vanadium. This is especially clear after 50 cycles where vanadium shows almost no redox activity while a capacity of 80 $\mathrm{mA} \mathrm{h}^{-1}$ is still measured.

We believe that the degradation of the material occurs when oxidized oxygen comes into contact with electrolyte salt where it can react with $\mathrm{F}^{-}$to form new stable vanadium compounds such as $\mathrm{VOF}_{3}$ according to the following proposed degradation reaction for the fully delithiated $\mathrm{Li}_{2} \mathrm{VO}_{3}$ (i.e., $\mathrm{VO}_{3}$ ) material

$$
\mathrm{VO}_{3}+\mathrm{PF}_{6}^{-}+\mathrm{Li}^{+}+\mathrm{e}^{-} \rightarrow \mathrm{VOF}_{3}+\mathrm{PO}_{2} \mathrm{~F}_{2}^{-}+\mathrm{LiF}
$$

This reaction is only believed to happen at the near-surface where the material is in contact with the electrolyte, and if $\mathrm{VOF}_{3}$ is assumed to be nonredox-active, it would explain why the bulk can be re-lithiated while the surface cannot. It also explains why less lithium can be inserted than extracted in the material, as well as the presence of $\mathrm{PO}_{x} \mathrm{~F}_{y}$ compounds, the decrease of lattice oxygen intensity, and the increased amounts of ionic fluorine as seen in the PES results. The $\mathrm{VOF}_{3}$ compound is expected to be incorporated with other inorganic degradation products in the interphase layer as illustrated by the blue and pink layers intermixing in Figure 8c. Upon further cycling, the degradation of the material spreads inward toward the bulk as fresh AM surfaces are exposed to the electrolyte.

\section{CONCLUSIONS AND OUTLOOK}

A comprehensive study of the vanadium redox activity and surface region evolution upon cycling of $\mathrm{Li}_{2} \mathrm{VO}_{2} \mathrm{~F}$ has been done by PES and XAS. Detailed spectroscopic analysis shows that the substantial capacity fading for the material results from the full and irreversible oxidation of vanadium to $\mathrm{V}^{5+}$ and the degradation of the metal oxyfluoride structure as a consequence of oxygen redox activity, as previously seen also for other Li-rich materials. ${ }^{24-27,29-33,96}$ The material degradation begins at the surface and moves toward the bulk with continued cycling. The results confirm that the AM is unstable under these cycling conditions, converting to new redoxinactive compounds, with a possible reaction pathway proposed involving partially oxidized lattice oxygen. Additionally, a continuous deposition and partial stripping on cycling of the interphase layer together with electrolyte degradation is seen at the electrode/electrolyte interface. The accumulation of a permanent interphase layer, dominated by insoluble inorganic compounds, occurs upon prolonged cycling.

The poor cycling performance of $\mathrm{Li}_{2} \mathrm{VO}_{2} \mathrm{~F}$ can now be attributed to an unstable surface layer that fails to passivate the AM surface, resulting in the consequential breakdown of the material because of detrimental reactions at the electrode/ electrolyte interface. These results highlight the need for a passivating surface coating and/or a stabilized lattice structure.
Protective surface coatings applied during synthesis and doping with other TMs have been found to successfully improve cycling performance for other Li-rich materials ${ }^{19,46-49}$ and will be the subject of further research on disordered rock-salt materials. If a successful combination of the AM and electrolyte that displays good capacity retention can be found, we believe that Li-rich disordered rock-salt materials are promising candidates as next-generation cathode materials.

\section{ASSOCIATED CONTENT}

\section{S Supporting Information}

The Supporting Information is available free of charge on the ACS Publications website at DOI: 10.1021/acs.chemmater.9b00829.

Overview of total sample composition, Li 1s spectra, and details on DFT simulations (PDF)

\section{AUTHOR INFORMATION}

\section{Corresponding Author}

*E-mail: maria.hahlin@physics.uu.se. ORCID

Ida Källquist: 0000-0001-8333-0088 Christian Baur: 0000-0002-1512-2735

Jolla Kullgren: 0000-0003-3570-0050

Kristina Edström: 0000-0003-4440-2952

Daniel Brandell: 0000-0002-8019-2801

Maria Hahlin: 0000-0002-5680-1216

\section{Author Contributions}

The manuscript was written through contributions of all the authors. All the authors have given approval to the final version of the manuscript.

\section{Notes}

The authors declare no competing financial interest.

\section{ACKNOWLEDGMENTS}

This project has received funding from the European Union's Horizon 2020 research and innovation program under grant agreement no. 711792 (LiRichFCC). The Swedish Research Council (2016-03545) and STandUP for Energy are acknowledged for financial support. The research leading to this result has been supported by the project CALIPSOplus under the grant agreement 730872 from the EU Framework Programme for Research and Innovation HORIZON 2020. We acknowledge Diamond Light Source for time on Beamline I09 under Proposal 19602 and HZB for allocated synchrotron radiation beamtime on beamline KMC-1 at BESSY II. Thanks are also due to the Swedish National Infrastructure for Computing (SNIC) at UPPMAX and NSC where the DFT simulations were performed, Prof. Tejs Vegge, Dr. Jinhyun Chang, and Dr. Simon Loftager at Danmarks Tekniske Universitet (DTU), and Fredrik Lindgren at Uppsala University for valuable discussion.

\section{REFERENCES}

(1) Yan, J.; Liu, X.; Li, B. Recent Progress in Li-Rich Layered Oxides as Cathode Materials for Li-Ion Batteries. RSC Adv. 2014, 4, 6326863284.

(2) Rozier, P.; Tarascon, J. M. Review-Li-Rich Layered Oxide Cathodes for Next-Generation Li-Ion Batteries: Chances and Challenges. J. Electrochem. Soc. 2015, 162, A2490-A2499. 
(3) Pralong, V.; Gopal, V.; Caignaert, V.; Duffort, V.; Raveau, B. Lithium-Rich Rock-Salt-Type Vanadate as Energy Storage Cathode: Li2-Xvo3. Chem. Mater. 2012, 24, 12-14.

(4) Sathiya, M.; et al. Reversible Anionic Redox Chemistry in HighCapacity Layered-Oxide Electrodes. Nat. Mater. 2013, 12, 827-835.

(5) Seo, D.-H.; Lee, J.; Urban, A.; Malik, R.; Kang, S.; Ceder, G. The Structural and Chemical Origin of the Oxygen Redox Activity in Layered and Cation-Disordered Li-Excess Cathode Materials. Nat. Chem. 2016, 8, 692-697.

(6) Saubanère, M.; McCalla, E.; Tarascon, J.-M.; Doublet, M.-L. The Intriguing Question of Anionic Redox in High-Energy Density Cathodes for Li-Ion Batteries. Energy Environ. Sci. 2016, 9, 984-991.

(7) Blomgren, G. E. The Development and Future of Lithium Ion Batteries. J. Electrochem. Soc. 2017, 164, A5019-A5025.

(8) Goodenough, J. B.; Park, K.-S. The Li-Ion Rechargeable Battery: A Perspective. J. Am. Chem. Soc. 2013, 135, 1167-1176.

(9) Armand, M.; Tarascon, J.-M. Building Better Batteries. Nature 2008, 451, 652-657.

(10) Chen, R.; Ren, S.; Yavuz, M.; Guda, A. A.; Shapovalov, V.; Witter, R.; Fichtner, M.; Hahn, H. Li+ Intercalation in Isostructural Li2vo3 and Li2vo2f with O2- and Mixed O2-/F- Anions. Phys. Chem. Chem. Phys. 2015, 17, 17288-17295.

(11) Recham, N.; Chotard, J.-N.; Dupont, L.; Delacourt, C.; Walker, W.; Armand, M.; Tarascon, J.-M. A 3.6V Lithium-Based Fluorosulphate Insertion Positive Electrode for Lithium-Ion Batteries. Nat. Mater. 2010, 9, 68-74.

(12) Chen, R.; Ren, S.; Knapp, M.; Wang, D.; Witter, R.; Fichtner, M.; Hahn, H. Disordered Lithium-Rich Oxyfluoride as a Stable Host for Enhanced Li+ Intercalation Storage. Adv. Energy Mater. 2015, 5, 1401814.

(13) Pereira, N.; Badway, F.; Wartelsky, M.; Gunn, S.; Amatucci, G. G. Iron Oxyfluorides as High Capacity Cathode Materials for Lithium Batteries. J. Electrochem. Soc. 2009, 156, A407-A416.

(14) Gutierrez, A.; Manthiram, A. Understanding the Effects of Cationic and Anionic Substitutions in Spinel Cathodes of Lithium-Ion Batteries. J. Electrochem. Soc. 2013, 160, A901-A905.

(15) Choi, W.; Manthiram, A. Superior Capacity Retention Spinel Oxyfluoride Cathodes for Lithium-Ion Batteries. Electrochem. SolidState Lett. 2006, 9, A245-A248.

(16) Bervas, M.; Klein, L. C.; Amatucci, G. G. Reversible Conversion Reactions with Lithium in Bismuth Oxyfluoride Nanocomposites. J. Electrochem. Soc. 2006, 153, A159-A170.

(17) Duttine, M.; et al. Tailoring the Composition of a Mixed Anion Iron-Based Fluoride Compound: Evidence for Anionic Vacancy and Electrochemical Performance in Lithium Cells. Chem. Mater. 2014, 26, 4190-4199.

(18) Wang, X.; et al. Structure Evolution and Thermal Stability of High-Energy- Density Li-Ion Battery Cathode Li2vo2f. J. Electrochem. Soc. 2017, 164, A1552-A1558.

(19) Ren, S.; Chen, R.; Maawad, E.; Dolotko, O.; Guda, A. A.; Shapovalov, V.; Wang, D.; Hahn, H.; Fichtner, M. Improved Voltage and Cycling for $\mathrm{Li}+$ Intercalation in High-Capacity Disordered Oxyfluoride Cathodes. Adv. Sci. 2015, 2, 1500128.

(20) Chernova, N. A.; Roppolo, M.; Dillon, A. C.; Whittingham, M. S. Layered Vanadium and Molybdenum Oxides: Batteries and Electrochromics. J. Mater. Chem. 2009, 19, 2526-2552.

(21) Sudant, G.; Baudrin, E.; Dunn, B.; Tarascon, J.-M. Synthesis and Electrochemical Properties of Vanadium Oxide Aerogels Prepared by a Freeze-Drying Process. J. Electrochem. Soc. 2004, 151, A666-A671.

(22) Bock, D. C.; Marschilok, A. C.; Takeuchi, K. J.; Takeuchi, E. S. A Kinetics and Equilibrium Study of Vanadium Dissolution from Vanadium Oxides and Phosphates in Battery Electrolytes: Possible Impacts on Icd Battery Performance. J. Power Sources 2013, 231, 219-225.

(23) Wang, J.; Liu, Z.; Yan, G.; Li, H.; Peng, W.; Li, X.; Song, L.; Shih, K. Improving the Electrochemical Performance of Lithium Vanadium Fluorophosphate Cathode Material: Focus on Interfacial Stability. J. Power Sources 2016, 329, 553-557.
(24) Yang, X.; Wang, D.; Yu, R.; Bai, Y.; Shu, H.; Ge, L.; Guo, H.; Wei, Q.; Liu, L.; Wang, X. Suppressed Capacity/Voltage Fading of High-Capacity Lithium-Rich Layered Materials Via the Design of Heterogeneous Distribution in the Composition. J. Mater. Chem. A 2014, 2, 3899-3911.

(25) Song, B.; Liu, Z.; Lai, M. O.; Lu, L. Structural Evolution and the Capacity Fade Mechanism Upon Long-Term Cycling in Li-Rich Cathode Material. Phys. Chem. Chem. Phys. 2012, 14, 12875-12883.

(26) Sathiya, M.; et al. Origin of Voltage Decay in High-Capacity Layered Oxide Electrodes. Nat. Mater. 2015, 14, 230-238.

(27) Armstrong, A. R.; Holzapfel, M.; Novák, P.; Johnson, C. S.; Kang, S.-H.; Thackeray, M. M.; Bruce, P. G. Demonstrating Oxygen Loss and Associated Structural Reorganization in the Lithium Battery Cathode Li[Ni0.2li0.2mn0.6]O2. J. Am. Chem. Soc. 2006, 128, 86948698.

(28) Mohanty, D.; Li, J.; Abraham, D. P.; Huq, A.; Payzant, E. A.; Wood, D. L.; Daniel, C. Unraveling the Voltage-Fade Mechanism in High-Energy-Density Lithium-Ion Batteries: Origin of the Tetrahedral Cations for Spinel Conversion. Chem. Mater. 2014, 26, 6272-6280.

(29) Lee, J.; Papp, J. K.; Clément, R. J.; Sallis, S.; Kwon, D.-H.; Shi, T.; Yang, W.; McCloskey, B. D.; Ceder, G. Mitigating Oxygen Loss to Improve the Cycling Performance of High Capacity CationDisordered Cathode Materials. Nat. Commun. 2017, 8, 981.

(30) Yabuuchi, N.; et al. High-Capacity Electrode Materials for Rechargeable Lithium Batteries: Li3nbo4-Based System with CationDisordered Rocksalt Structure. Proc. Natl. Acad. Sci. U.S.A. 2015, 112, 7650-7655.

(31) Yabuuchi, N.; et al. Origin of Stabilization and Destabilization in Solid-State Redox Reaction of Oxide Ions for Lithium-Ion Batteries. Nat. Commun. 2016, 7, 13814.

(32) Lee, J.; Seo, D.-H.; Balasubramanian, M.; Twu, N.; Li, X.; Ceder, G. A New Class of High Capacity Cation-Disordered Oxides for Rechargeable Lithium Batteries: Li-Ni-Ti-Mo Oxides. Energy Environ. Sci. 2015, 8, 3255-3265.

(33) Wang, R.; Li, X.; Liu, L.; Lee, J.; Seo, D.-H.; Bo, S.-H.; Urban, A.; Ceder, G. A Disordered Rock-Salt Li-Excess Cathode Material with High Capacity and Substantial Oxygen Redox Activity: Li1.25nb0.25mn0.5o2. Electrochem. Commun. 2015, 60, 70-73.

(34) Hong, J.; Lim, H.-D.; Lee, M.; Kim, S.-W.; Kim, H.; Oh, S.-T.; Chung, G.-C.; Kang, K. Critical Role of Oxygen Evolved from Layered Li-Excess Metal Oxides in Lithium Rechargeable Batteries. Chem. Mater. 2012, 24, 2692-2697.

(35) Peled, E. The Electrochemical Behavior of Alkali and Alkaline Earth Metals in Nonaqueous Battery Systems-the Solid Electrolyte Interphase Model. J. Electrochem. Soc. 1979, 126, 2047-2051.

(36) Peled, E.; Menkin, S. Review-Sei: Past, Present and Future. J. Electrochem. Soc. 2017, 164, A1703-A1719.

(37) Qian, Y.; Niehoff, P.; Börner, M.; Grützke, M.; Mönnighoff, X.; Behrends, P.; Nowak, S.; Winter, M.; Schappacher, F. M. Influence of Electrolyte Additives on the Cathode Electrolyte Interphase (Cei) Formation on Lini $1 / 3 \mathrm{mn} 1 / 3 \mathrm{co} 1 / 3 \mathrm{o} 2$ in Half Cells with Li Metal Counter Electrode. J. Power Sources 2016, 329, 31-40.

(38) Zhang, J.-N.; Li, Q.; Wang, Y.; Zheng, J.; Yu, X.; Li, H. Dynamic Evolution of Cathode Electrolyte Interphase (Cei) on High Voltage Licoo2 Cathode and Its Interaction with Li Anode. Energy Storage Mater. 2018, 14, 1-7.

(39) Zuo, X.; Fan, C.; Xiao, X.; Liu, J.; Nan, J. High-Voltage Performance of Licoo2/Graphite Batteries with Methylene Methanedisulfonate as Electrolyte Additive. J. Power Sources 2012, 219, 94-99.

(40) Edström, K.; Gustafsson, T.; Thomas, J. O. The CathodeElectrolyte Interface in the Li-Ion Battery. Electrochim. Acta 2004, 50, 397-403.

(41) Malmgren, S.; Ciosek, K.; Hahlin, M.; Gustafsson, T.; Gorgoi, M.; Rensmo, H.; Edström, K. Comparing Anode and Cathode Electrode/Electrolyte Interface Composition and Morphology Using Soft and Hard X-Ray Photoelectron Spectroscopy. Electrochim. Acta 2013, 97, 23-32. 
(42) Lee, T. J.; Kim, H.-s.; Hwang, H. S.; Soon, J.; Jung, J.; Ryu, J. H.; Oh, S. M. Solid Permeable Interface (Spi) on a High-Voltage Positive Electrode of Lithium-Ion Batteries. J. Electrochem. Soc. 2018, 165, A575-A583.

(43) Aurbach, D.; Markovsky, B.; Salitra, G.; Markevich, E.; Talyossef, Y.; Koltypin, M.; Nazar, L.; Ellis, B.; Kovacheva, D. Review on Electrode-Electrolyte Solution Interactions, Related to Cathode Materials for Li-Ion Batteries. J. Power Sources 2007, 165, 491-499.

(44) Gauthier, M.; et al. Electrode-Electrolyte Interface in Li-Ion Batteries: Current Understanding and New Insights. J. Phys. Chem. Lett. 2015, 6, 4653-4672.

(45) $\mathrm{Xu}, \mathrm{K}$. Electrolytes and Interphases in Li-Ion Batteries and Beyond. Chem. Rev. 2014, 114, 11503-11618.

(46) Zhao, T.; Li, L.; Chen, R.; Wu, H.; Zhang, X.; Chen, S.; Xie, M.; Wu, F.; Lu, J.; Amine, K. Design of Surface Protective Layer of Lif/Fef3 Nanoparticles in Li-Rich Cathode for High-Capacity Li-Ion Batteries. Nano Energy 2015, 15, 164-176.

(47) Zheng, J.; Gu, M.; Xiao, J.; Polzin, B. J.; Yan, P.; Chen, X.; Wang, C.; Zhang, J.-G. Functioning Mechanism of Alf3 Coating on the Li- and Mn-Rich Cathode Materials. Chem. Mater. 2014, 26, 6320-6327.

(48) Xu, M.; Chen, Z.; Zhu, H.; Yan, X.; Li, L.; Zhao, Q. Mitigating Capacity Fade by Constructing Highly Ordered Mesoporous Al2o3/ Polyacene Double-Shelled Architecture in Li-Rich Cathode Materials. J. Mater. Chem. A 2015, 3, 13933-13945.

(49) Liu, W.; Oh, P.; Liu, X.; Myeong, S.; Cho, W.; Cho, J. Countering Voltage Decay and Capacity Fading of Lithium-Rich Cathode Material at $60{ }^{\circ} \mathrm{C}$ by Hybrid Surface Protection Layers. $A d v$. Energy Mater. 2015, 5, 1500274.

(50) Philippe, B.; Hahlin, M.; Edström, K.; Gustafsson, T.; Siegbahn, H.; Rensmo, H. Photoelectron Spectroscopy for Lithium Battery Interface Studies. J. Electrochem. Soc. 2016, 163, A178-A191.

(51) Cherkashinin, G.; Motzko, M.; Schulz, N.; Späth, T.; Jaegermann, W. Electron Spectroscopy Study of $\mathrm{Li}[\mathrm{Ni}, \mathrm{Co}, \mathrm{Mn}] \mathrm{O} 2 /$ Electrolyte Interface: Electronic Structure, Interface Composition, and Device Implications. Chem. Mater. 2015, 27, 2875-2887.

(52) Schulz, N.; Hausbrand, R.; Wittich, C.; Dimesso, L.; Jaegermann, W. Xps-Surface Analysis of Sei Layers on Li-Ion Cathodes: Part Ii. Sei-Composition and Formation inside Composite Electrodes. J. Electrochem. Soc. 2018, 165, A833-A846.

(53) Malmgren, S.; Rensmo, H.; Gustafsson, T.; Gorgoi, M.; Edström, K. Nondestructive Depth Profiling of the Solid Electrolyte Interphase on Lifepo4 and Graphite Electrodes. ECS Trans. 2010, 25, 201-210.

(54) Edström, K.; Herstedt, M.; Abraham, D. P. A New Look at the Solid Electrolyte Interphase on Graphite Anodes in Li-Ion Batteries. J. Power Sources 2006, 153, 380-384.

(55) McBreen, J.; O'Grady, W. E.; Pandya, K. I. Exafs: A New Tool for the Study of Battery and Fuel Cell Materials. J. Power Sources 1988, 22, 323-340.

(56) Lin, F.; et al. Synchrotron X-Ray Analytical Techniques for Studying Materials Electrochemistry in Rechargeable Batteries. Chem. Rev. 2017, 117, 13123-13186.

(57) Giorgetti, M.; Passerini, S.; Smyrl, W. H.; Mukerjee, S.; Yang, X. Q.; McBreen, J. In Situ X-Ray Absorption Spectroscopy Characterization of V2O5 Xerogel Cathodes Upon Lithium Intercalation. J. Electrochem. Soc. 1999, 146, 2387-2392.

(58) Balasubramanian, M.; Sun, X.; Yang, X. Q.; McBreen, J. In Situ $\mathrm{X}$-Ray Diffraction and X-Ray Absorption Studies of High-Rate Lithium-Ion Batteries. J. Power Sources 2001, 92, 1-8.

(59) Ye, Y.; Wu, C. H.; Zhang, L.; Liu, Y.-S.; Glans-Suzuki, P.-A.; Guo, J. Using Soft X-Ray Absorption Spectroscopy to Characterize Electrode/Electrolyte Interfaces in-Situ and Operando. J. Electron Spectrosc. Relat. Phenom. 2017, 221, 2-9.

(60) Baur, C.; Chable, J.; Klein, F.; Chakravadhanula, V. S. K.; Fichtner, M. Reversible Delithiation of Disordered Rock Salt Livo2. ChemElectroChem 2018, 5, 1484-1490.
(61) Lee, T.-L.; Duncan, D. A. A Two-Color Beamline for Electron Spectroscopies at Diamond Light Source. Synchrotron Radiat. News 2018, 31, 16-22.

(62) Seah, M. P.; Dench, W. A. Quantitative Electron Spectroscopy of Surfaces: A Standard Data Base for Electron Inelastic Mean Free Paths in Solids. Surf. Interface Anal. 1979, 1, 2-11.

(63) Painter, L. R.; Arakawa, E. T.; Williams, M. W.; Ashley, J. C. Optical Properties of Polyethylene: Measurement and Applications. Radiat. Res. 1980, 83, 1-18.

(64) Powell, C. J.; Jablonski, A. Nist Electron Inelastic-Mean-Free-Path Database 71, version 1.0; NIST, 1999.

(65) Schaefers, F.; Mertin, M.; Gorgoi, M. Kmc-1: A High Resolution and High Flux Soft X-Ray Beamline at Bessy. Rev. Sci. Instrum. 2007, 78, 123102.

(66) Yeh, J. J.; Lindau, I. Atomic Subshell Photoionization Cross Sections and Asymmetry Parameters: 1 Z 103. At. Data Nucl. Data Tables 1985, 32, 1-155.

(67) Scofield, J. H. Theoretical Photoionization Cross Sections from 1 to $1500 \mathrm{keV}$; California University, 1973.

(68) Moulder, J. F.; Chastain, J. Handbook of X-ray Photoelectron Spectroscopy: A Reference Book of Standard Spectra for Identification and Interpretation of XPS Data; Physical Electronics Division, PerkinElmer Corporation, 1992.

(69) Scofield, J. H. Hartree-Slater Subshell Photoionization CrossSections at 1254 and 1487 Ev. J. Electron Spectrosc. Relat. Phenom. 1976, 8, 129-137.

(70) Powell, C. J.; Jablonski, A. Progress in Quantitative Surface Analysis by X-Ray Photoelectron Spectroscopy: Current Status and Perspectives. J. Electron Spectrosc. Relat. Phenom. 2010, 178-179, 331-346.

(71) Malmgren, S.; Ciosek, K.; Lindblad, R.; Plogmaker, S.; Kühn, J.; Rensmo, H.; Edström, K.; Hahlin, M. Consequences of Air Exposure on the Lithiated Graphite Sei. Electrochim. Acta 2013, 105, 83-91.

(72) Somerville, L.; Bareño, J.; Jennings, P.; McGordon, A.; Lyness, C.; Bloom, I. The Effect of Pre-Analysis Washing on the Surface Film of Graphite Electrodes. Electrochim. Acta 2016, 206, 70-76.

(73) Beamson, G. In High Resolution XPS of Organic Polymers: The Scienta Esca300 Database; Briggs, D., Ed.; Wiley: Chichester, England, 1992.

(74) Biesinger, M. C.; Lau, L. W. M.; Gerson, A. R.; Smart, R. S. C. Resolving Surface Chemical States in Xps Analysis of First Row Transition Metals, Oxides and Hydroxides: $\mathrm{Sc}, \mathrm{Ti}, \mathrm{V}, \mathrm{Cu}$ and $\mathrm{Zn}$. Appl. Surf. Sci. 2010, 257, 887-898.

(75) Momma, K.; Izumi, F. Vesta 3 for Three-Dimensional Visualization of Crystal, Volumetric and Morphology Data. J. Appl. Crystallogr. 2011, 44, 1272-1276.

(76) Chen, R.; Maawad, E.; Knapp, M.; Ren, S.; Beran, P.; Witter, R.; Hempelmann, R. Lithiation-Driven Structural Transition of Vo2f into Disordered Rock-Salt Lixvo2f. RSC Adv. 2016, 6, 65112-65118.

(77) Pérez-Flores, J. C.; Villamor, R.; Ávila-Brande, D.; Gallardo Amores, J. M.; Morán, E.; Kuhn, A.; García-Alvarado, F. Vo2f: A New Transition Metal Oxyfluoride with High Specific Capacity for Li Ion Batteries. J. Mater. Chem. A 2015, 3, 20508-20515.

(78) Wang, X.; et al. Structural Changes in a High-Energy Density Vo2f Cathode Upon Heating and Li Cycling. ACS Appl. Energy Mater. 2018, 1, 4514-4521.

(79) Groult, H.; Devilliers, D.; Kumagai, N.; Nakajima, T.; Matsuo, Y. Vanadium Oxide Fluoride-Graphite Intercalation Compounds: Structural Characteristics and Electrochemical Insertion of Lithium Cations. J. Electrochem. Soc. 1996, 143, 2093-2099.

(80) Assat, G.; Foix, D.; Delacourt, C.; Iadecola, A.; Dedryvère, R.; Tarascon, J.-M. Fundamental Interplay between Anionic/Cationic Redox Governing the Kinetics and Thermodynamics of Lithium-Rich Cathodes. Nat. Commun. 2017, 8, 2219.

(81) Dupin, J.-C.; Gonbeau, D.; Vinatier, P.; Levasseur, A. Systematic Xps Studies of Metal Oxides, Hydroxides and Peroxides. Phys. Chem. Chem. Phys. 2000, 2, 1319-1324.

(82) Foix, D.; Sathiya, M.; McCalla, E.; Tarascon, J.-M.; Gonbeau, D. X-Ray Photoemission Spectroscopy Study of Cationic and Anionic 
Redox Processes in High-Capacity Li-Ion Battery Layered-Oxide Electrodes. J. Phys. Chem. C 2016, 120, 862-874.

(83) Wong, J.; Lytle, F. W.; Messmer, R. P.; Maylotte, D. H. K-Edge Absorption Spectra of Selected Vanadium Compounds. Phys. Rev. B: Condens. Matter Mater. Phys. 1984, 30, 5596-5610.

(84) House, R. A.; Jin, L.; Maitra, U.; Tsuruta, K.; Somerville, J. W.; Förstermann, D. P.; Massel, F.; Duda, L.; Roberts, M. R.; Bruce, P. G. Lithium Manganese Oxyfluoride as a New Cathode Material Exhibiting Oxygen Redox. Energy Environ. Sci. 2018, 11, 926-932.

(85) Li, X.; Qiao, Y.; Guo, S.; Jiang, K.; Ishida, M.; Zhou, H. A New Type of Li-Rich Rock-Salt Oxide Li2ni1/3ru2/3o3 with Reversible Anionic Redox Chemistry. Adv. Mater. 2019, 31, 1807825.

(86) Richards, W. D.; Dacek, S. T.; Kitchaev, D. A.; Ceder, G. Fluorination of Lithium-Excess Transition Metal Oxide Cathode Materials. Adv. Energy Mater. 2018, 8, 1701533.

(87) Aurbach, D.; Gamolsky, K.; Markovsky, B.; Salitra, G.; Gofer, Y.; Heider, U.; Oesten, R.; Schmidt, M. The Study of Surface Phenomena Related to Electrochemical Lithium Intercalation into $\mathrm{Li}$ X Mo Y Host Materials $(\mathrm{M}=\mathrm{Ni}, \mathrm{Mn})$. J. Electrochem. Soc. 2000, 147, 1322-1331.

(88) Bar-Tow, D.; Peled, E.; Burstein, L. A Study of Highly Oriented Pyrolytic Graphite as a Model for the Graphite Anode in Li-Ion Batteries. J. Electrochem. Soc. 1999, 146, 824-832.

(89) Younesi, R.; Christiansen, A. S.; Scipioni, R.; Ngo, D.-T.; Simonsen, S. B.; Edström, K.; Hjelm, J.; Norby, P. Analysis of the Interphase on Carbon Black Formed in High Voltage Batteries. J. Electrochem. Soc. 2015, 162, A1289-A1296.

(90) Andersson, A. M.; Abraham, D. P.; Haasch, R.; MacLaren, S.;

Liu, J.; Amine, K. Surface Characterization of Electrodes from High Power Lithium-Ion Batteries. J. Electrochem. Soc. 2002, 149, A1358A1369.

(91) Schulz, N.; Hausbrand, R.; Dimesso, L.; Jaegermann, W. XpsSurface Analysis of Sei Layers on Li-Ion Cathodes: Part I. Investigation of Initial Surface Chemistry. J. Electrochem. Soc. 2018, 165, A819-A832.

(92) Ensling, D.; Stjerndahl, M.; Nytén, A.; Gustafsson, T.; Thomas, J. O. A Comparative Xps Surface Study of Li 2 Fesio 4/C Cycled with Litfsi-and Lipf 6-Based Electrolytes. J. Mater. Chem. 2009, 19, 82-88.

(93) Herstedt, M.; Stjerndahl, M.; Nytén, A.; Gustafsson, T.; Rensmo, H.; Siegbahn, H.; Ravet, N.; Armand, M.; Thomas, J. O.; Edström, K. Surface Chemistry of Carbon-Treated Lifepo4 Particles for Li-Ion Battery Cathodes Studied by Pes. Electrochem. Solid-State Lett. 2003, 6, A202-A206.

(94) Li, H.; Richter, G.; Maier, J. Reversible Formation and Decomposition of Lif Clusters Using Transition Metal Fluorides as Precursors and Their Application in Rechargeable Li Batteries. Adv. Mater. 2003, 15, 736-739.

(95) Ji, H.; et al. Hidden Structural and Chemical Order Controls Lithium Transport in Cation-Disordered Oxides for Rechargeable Batteries. Nat. Commun. 2019, 10, 592.

(96) Yu, D. Y. W.; Yanagida, K. Structural Analysis of Li2mno3 and Related Li-Mn-O Materials. J. Electrochem. Soc. 2011, 158, A1015A1022. 